\title{
THE DETERMINANTS OF MEDICINE USE IN ROMANIA
}

\author{
DĂNUȚ-VAsILE JEMnA ${ }^{\mathrm{i}}$, LuCIA CIUBOTARU ${ }^{\mathrm{ii}}$, MiHAELA DAVID ${ }^{\mathrm{iii}}$
}

\begin{abstract}
For Romania's population, the highest share of total health services use corresponds to the use of pharmaceutical services, for which the state covers less than $60 \%$ of health expenditure. This leads people to use their financial resources to cover their health needs, which creates further disparities in the use of medicines. Therefore, the aim of this paper is to study the impact of socio-economic, health and health behaviour factors on the use of prescribed and self-prescribed medicines using probit models. This analysis is based on data from the European Health Interview Survey 2014 (EHIS 2014) and is explored at the whole population level and separately for two age groups (less than 65 years, 65 years and over). Overall, the empirical findings highlight that the determinants of pharmaceutical consumption differ by type of medicines and age group.
\end{abstract}

Keywords: Romanian public health system, medicines use, EHIS 2014, recursive bivariate probit model.

JEL Classification: $I 12, I 18, C 25, C 26$

\section{INTRODUCTION}

The use of medicines is a major issue involving both policy decisions and the management of health systems, as well as important manufacturing and distribution industries. European policy-makers agree with the common objectives that health systems should ensure accessibility, quality and equity of medicines. But different countries have different approaches and therefore take divergent and sometimes contradictory measures. The diversity of health systems leads to the question of what is the best solution for different groups of people, especially those who are vulnerable and exposed to frequent changes in the system. Today, many

\footnotetext{
${ }^{i}$ Alexandru Ioan Cuza University of Iaşi, Faculty of Economics and Business Administration, Iaşi, Romania, danut.jemna@uaic.ro

ii Alexandru Ioan Cuza University of Iaşi, Doctoral School of Economics and Business Administration, Iaşi, Romania, luciaciubotaru93@gmail.com

iii „Gh. Zane“ Institute for Economic and Social Research - Romanian Academy, Iaşi Branch, Iaşi, Romania, mihaela_david88@yahoo.com
} 
governments face a pressing problem caused by the growing demand for healthcare services, which is higher than the share of health gross domestic product and higher than healthcare budgets. Governments therefore need to ensure that resources are used efficiently and avoid wastage by targeting the vulnerable in the right way.

The complex phenomenon of medicines use is little studied in Romania. This contrasts with changes in the behaviour and needs of the population in terms of use of health services, on the one hand, and changes in the public health system, on the other. Over the last 30 years, public health in Romania has faced a decrease in financial support and a shift from a strongly centralized system to one in which health services are partly covered by the state. Even though the health insurance system provides a full package of services, around $11 \%$ of the population remains uninsured and is entitled to only a minimum package of services (European Comission,2019). Moreover, due to public insufficient funding, patient spending accounts for about one-fifth of current health expenditure in Romania (20.5\% in 2017, compared to $15.8 \%$ in the EU), and most of this expenditure is for the purchase of medicines outside hospitals. Co-payments for these prescription medicines in outpatient care range from $10 \%$ of the consumer price of generic medicines to $80 \%$ for new prescription medicines. Thus, lack of government support leads people to use their own resources to afford needed medicines, which could create disparities in the use of this healthcare service.

In addition to the specificities of the health system, the demand for and consumption of pharmaceuticals is strongly correlated with the health status of the population, as well as a number of socio-economic and demographic determinants. The behaviour of the population with regard to the use of medicines requires constant research to identify these factors and also to analyze the existence of possible inequalities in access to the use of health services for a given population. To our knowledge, there is a lack of studies analyzing the consumption of medicines among the Romanian population. Only one study, conducted on eight Central and Eastern European countries, has investigated the impact of socioeconomic determinants on the consumption of prescribed and non-prescribed medicines. This research outlines for Romania a positive relationship between a higher socioeconomic status and an increasing trend in prescription drug consumption (Vogler et al.,2015). Other studies refer either to the consumption of illicit medicines (Elekes and Kovacs,2002) or to the study of specific categories of people or medicines (Manole et al.,2017; Tarciuc et al.,2020).

This research addresses this gap in the literature on the need to study the use of medicines in Romania. After a long period of transition in the health system and 
after important changes in the health and behaviour of the population, identifying the determinants of medicines use can serve policy makers and contribute to a deeper understanding of the use of this health service in Romania. The novelty of our work is therefore threefold. First, it provides an overall analysis of medicine use in relation to a set of determinants at national level. To our knowledge, no such studies have been conducted using the same data provided by EHIS 2014. Thus, it provides valuable information for policy makers on how to improve solutions or implement policies to ensure access for the whole population to both prescription and non-prescription medicines. Second, the empirical approach used allows us to address the endogeneity problem caused by the possible reverse causality of medication use in relation to health status. Third, regression analysis is employed for both the whole population and two major age categories to better highlight the specificity of medication use in a nationally representative sample.

The rest of this paper is organized as follows. Section 2 reviews a number of findings from empirical studies examining the determinants of prescription and non-prescription drug use. Section 3 presents the data and methodology used. Section 4 presents and discusses the main empirical results. The study ends with a series of concluding remarks and references.

\section{LITERATURE REVIEW}

A large body of the literature emphasizes a significant impact of socioeconomic, demographic, cultural, and health factors on the use of medicines in any adult population. The role of these determinants has been analyzed for the two types of medicines: prescription medicines and non-prescription medicines. According to existing literature, the frequency of medication use, as well as the amount of medication consumed, is strongly influenced by the health status of the population. People reporting various physical or mental health problems or those who report being less healthy tend to consume more medication than healthy people (Johnson and Pope,1983; Vogler et al.,2015).

Of the demographic factors, the literature recommends analyzing the impact of age and gender on medicine use. In terms of gender, women tend to use more medicines than men. Findings from the literature show that this is generally true for both the use of non-prescription medicines (Johnson and Pope,1983; Carrasco-Garrido et al.,2014; Vogler et al.,2015) and the use of prescription medicines (Furu et al.,1997; Vogler et al.,2015). This is explained by the transformations women go through in their reproductive lives and the fact that 
women with a diagnosis tend to use medication more than men in the same situation (Eggen,1997; Daban et al.,2010). It should also be noted that both men and women use more prescription drugs than non-prescription drugs (Mayer and Österle,2015). The age of the individuals also has a significant impact on medication. Most studies show that older people are more likely to use nonprescription medicines than younger people and adults, and this is also true for prescription medicines (Vogler et al.,2015). The risk of medication use increases with age in both sexes. However, in a study conducted on the Barcelona population, Daban et al. (2010) pointed out that prescription drugs increase with age, while over-the-counter drugs decrease with age.

Studies on representative samples show that socio-economic position is a category of factors with a significant impact on the use of medicines. Socioeconomic position is usually measured by education, occupational position and income (Nielsen et al.,2003). Empirical evidence has been found supporting that more educated individuals are inclined to use non-prescription medications more often (Johnson and Pope,1983; Carrasco-Garrido et al.,2014; Vogler et al.,2015). On the other hand, arguments have been found supporting a negative relationship between education level and prescription drug use (Nielsen et al.,2003; Mayer and Österle,2015). Regarding income level, the results for non-prescription medicines are not decisive. There are studies showing that income has a significant impact on medication use (Carrasco-Garrido et al.,2014), while others found no support for a significant relationship between variables (Vogler et al.,2015). In terms of prescription drug consumption, it is thought that higher income individuals have greater access to medicines and then tend to consume more than lower income individuals (Daban et al.,2010; Vogler et al.,2015). Labour market participation is also a significant factor in people's medicine consumption behaviour. Those who do not work tend to use prescription medicines more often (Mayer and Österle,2015).

The importance of cultural factors on drug use has been studied to highlight differences among countries. A study of 27 European countries shows strong evidence of the impact of cultural dimensions on prescription and non-prescription antibiotic use (Deschepper et al.,2008). Another example is a study of the Israel population, which shows that cultural group is a determinant of drug use (LernerGeva et al.,2017). According to existing literature, ethnicity also plays a determinant role for prescription drug use (Nielsen et al.,2003; Vie et al.,2017). 


\section{DATA AND Methodology}

\subsection{Data used}

The individualized secondary data retrieved from the second wave of EHIS 2014 for Romania were used to conduct our study on the determinants of medicines use. The EHIS 2014 is composed of three health modules, i.e. health status, healthcare utilization, health determinants, and a module that includes background variables on demographics and socio-economic status of the population living in non-institutional households residing in the country. After excluding observations without complete information, our final sample consists of 16411 observations.

The variables used in the present analysis have been shown to be important in public health studies and are consistent with the purpose of this study. Therefore, dependent variables are assessed based on questions on individual health care utilization. Of this group of indicators, those of interest are related to prescription medication use and self-medication (use $v s$. non-use) in the last two weeks.

The independent variables are divided into three major topics, such as individual characteristics, health status and variables describing different health behaviours. Individual characteristics correspond to demographic and socioeconomic determinants such as age, gender, education level, marital status, occupational status, and income level. To measure health status, individuals were asked how their health status was in general, with the optional responses: very good, good, average, poor and very poor. According to previous research (Molarius et al.,2007; Rocca et al.,2015; Jemna and David,2020), in regression analyses, the last two categories, very poor and poor, collapsed to poor. The third class of independent variables comprises individual and environmental determinants describing four different health behaviours, i.e. body mass index, tobacco and alcohol consumption, and a nutrition index based on fruit and vegetable consumption.

\subsection{Empirical strategy}

According to the existing literature and the nature of our outcome variables, we employed a probit regression model. Nevertheless, the potential reverse causality between health status and medicine use may lead to endogeneity and, implicitly, to biased estimates. The impact of health status on the use of medicine is quite obvious, but the reverse causality between the two variables is based on the idea that medicine use may determine the health status of individuals due to the side effects of the consumption of medical drugs. To tackle the potential endogeneity issue of health status, we employed a recursive bivariate probit model 
that involves the use of instrumental variables estimation (Maddala,1983; Ancelot et al.,2018). Instruments are explanatory variables that have an impact on health status but do not directly explain the probability of using medication, meaning that the effect of instrumental variables on medicines use is captured indirectly via health status. One instrumental variable was considered, namely the degree of concern shown by other people in what the person is doing as a proxy for people's social environment (Ancelot et al.,2020). We will therefore, in a second set of models, simultaneously estimate the discretized health status index and the probability of using medications.

Next, different robustness checks are performed to test the two estimation approaches (probit and recursive bivariate probit). In a recursive bivariate probit model, the likelihood ratio (LR) test is used to test for exogeneity and the overidentification test is used to check the validity of the instrumental variable. In addition, the association between medication use and its determinants was explored both for the whole population (classifying all respondents as a homogeneous group) and separately for two age groups (15-64 years and 65 years and over). Stratification of the sample allowed to account for variations in health between age groups that may affect the use of both prescription and non-prescription medicines.

\section{RESUlTS AND DISCUSSIONS}

\subsection{Descriptive statistics}

Table 1 provides summary statistics for the outcome variables and Tables A1A2 (in the Appendix) for the characteristics of individuals, both overall and stratified by the two age groups. Descriptive analysis of the data showed that in all three samples, the majority of respondents reported not using any type of medication. The only exception can be seen in the case of the age group 65 years and over, who reported using more prescription drugs. In addition, regardless of both age group and type of medication, the descriptive statistics presented in Tables A1-A2 suggest that medication use is more common among women than men.

Table 1 Medicine use, both for the entire population and stratified by age group

\begin{tabular}{|clccc|}
\hline Medicine use & & \multicolumn{3}{c}{$\begin{array}{c}\text { 65 Years Age } \begin{array}{c}\text { T65 Years Age } \\
\text { Group (\%) }\end{array} \\
\text { Group (\%) }\end{array}$} \\
\hline Non-prescribed medicines & No & 84.03 & 85.64 & 79.69 \\
& Yes & 15.97 & 14.36 & 20.31 \\
Prescribed medicines & No & 73.03 & 85.17 & 40.25 \\
& Yes & 26.97 & 14.83 & 59.75 \\
\hline
\end{tabular}

Source: Authors' computation 
Descriptive results on the characteristics of respondents who used prescription drugs are presented in Table A1. Overall, the majority of users are married, female and older. More than two thirds of the population reported that the last level of education attained was secondary. It is important to note that the age groups of consumers are not balanced, with only $0.87 \%$ of respondents in the $15-24$ age group. In terms of household income level, respondents are fairly evenly distributed, but self-reported employment status is, for more than $80 \%$ of them, unemployed. More than half of them reported a moderate good general health. In terms of factors related to individuals' health behaviour, although it is difficult to distinguish between users and non-users of prescription drugs in relation to BMI, the majority of individuals reported being non-users, regardless of their smoking, drinking and eating habits. In the 15-64 age group, more than half of consumers are married women. The vast majority in this group have at most a secondary education obtained $(>84 \%)$, however, about two-thirds reported being unemployed $(60.79 \%)$. In terms of income level, more than $66 \%$ of them stated that their income is at least in the range between the second and third quintile. The health status for about $30 \%$ of adult consumers is good and very good and only $19.97 \%$ reported poor health. This is also reflected in the very high percentages related to each of the determinants describing individuals' health behaviour, given that the vast majority of them said that they do not use prescription medications. Older consumers of prescription drugs are mostly women, mostly married and with a secondary education. In contrast to adult consumers, $68 \%$ of elderly reported that their household income level was at most in the second and third quintile range, and over $30 \%$ reported poor or very poor health. As for the health behaviour indicators, it is observed that for this category of individuals the use of prescription drugs is in a higher percentage attributed to those who have weight problems and bad smoking, drinking, and eating habits.

Table A2 is dedicated to presenting the characteristics of respondents who use non-prescription medicines. More than $63 \%$ of them are women, married, adults, and with secondary education level. Again, respondents were almost evenly split in each household income category and more than $57 \%$ of them reported being unemployed. In terms of health status, more than half of the respondents reported good or very good overall health, an observation that is supported by the health behaviour of the respondents, given that the majority reported not using nonprescription medication, regardless of BMI or other health habits. Most adult users of over-the-counter drugs are female, married, and $80 \%$ of them reported having a secondary education degree. The most frequent reported household income levels 
are at the upper bound $(>51 \%$, respectively), with the majority of respondents being employed. At the same time, over $72 \%$ of consumers rated their health as good or very good, which again could also be related to their smoking, drinking and eating habits. In the case of older consumers of non-prescription medicines, the same characteristics of the majority were found, namely female, married and with a secondary education. Although most of them reported having health problems, their use of non-prescription medicines is very low related to their behaviour towards health.

\subsection{Main results}

In this study, empirical results are presented for only one specification of the regression models, depending on the significance of endogeneity and overidentification tests (Tables 2-3). In other words, if the test result indicates the presence of endogeneity, then the results of the recursive bivariate probit models are discussed. Otherwise, the results of multiple probit regressions are considered. In this sense, the results of the overidentification test reveal that the coefficients corresponding to the instrumental variable, i.e. the degree of concern shown by other people about what the person does, are jointly zero in the equations on medicine use. These results show that the chosen instrumental variables do not have a direct impact on the outcome variables and can therefore be used in recursive bivariate probit estimation. However, the LR statistics show that reverse causality is not confirmed for the use of non-prescription medicines at the population level and among the adult group (Table 3). Therefore, for the two cases, the results presented and discussed correspond to probit regression model.

Table 2 presents the empirical results on the relationship between prescription drug use and individual characteristics, both for the whole population (Column 1) and for each age group, adults (Column 3) and the elderly (Column 4).

Table 2 The association between prescribed medicine use and its determinants, in total population and stratified by age group

\begin{tabular}{|c|c|c|c|}
\hline \multirow{2}{*}{ Variables } & Total & $\begin{array}{c}\text { <65 Years Age } \\
\text { Group }\end{array}$ & $\begin{array}{c}\geq 65 \text { Years Age } \\
\text { Group }\end{array}$ \\
\hline & $\begin{array}{l}\text { Recursive Bivariate } \\
\text { Probit Model }\end{array}$ & $\begin{array}{l}\text { Recursive Bivariate } \\
\text { Probit Model }\end{array}$ & $\begin{array}{l}\text { Recursive Bivariate } \\
\text { Probit Model }\end{array}$ \\
\hline Intercept & $0.6806^{* * *}$ & $0.8197^{* * *}$ & $0.4634^{* *}$ \\
\hline Age (15-24) & $-0.6528^{* * *}$ & $-0.3863^{* * *}$ & - \\
\hline Age (25-44) & $-0.7839^{* * *}$ & $-0.5549^{* * *}$ & - \\
\hline Age (45-64) & $-0.2138^{* * *}$ & - & - \\
\hline Age (65-74) & $-0.1344^{* *}$ & - & $-0.1764^{* * *}$ \\
\hline Age (75-79) & 0.0434 & - & 0.0261 \\
\hline
\end{tabular}




\begin{tabular}{|c|c|c|c|}
\hline & & < 65 Years Age & $\geq 65$ Years Age \\
\hline Variables & $\frac{\text { Total }}{2}$ & & \\
\hline & $\begin{array}{l}\text { Recursive Bivariate } \\
\text { Probit Model }\end{array}$ & $\begin{array}{l}\text { Recursive Bivariate } \\
\text { Probit Model }\end{array}$ & $\begin{array}{l}\text { Recursive Bivariate } \\
\text { Probit Model }\end{array}$ \\
\hline Gender (Male) & $-0.0745^{* * *}$ & $-0.0746^{*}$ & 0.0231 \\
\hline Education (Secondary) & 0.0221 & 0.0146 & -0.0364 \\
\hline Education (Tertiary) & $0.1131 *$ & $0.2617^{* *}$ & -0.0860 \\
\hline Marital_Status (Divorced) & 0.0651 & 0.0605 & 0.0880 \\
\hline Marital_Status (Married) & $0.1576^{* *}$ & 0.1350 * & 0.2476 \\
\hline Marital_Status (Widowed) & $0.2048^{* * *}$ & $0.2759^{* * *}$ & 0.2590 * \\
\hline Employment (Employed) & $-0.2610^{* * *}$ & $-0.2236^{* * *}$ & - \\
\hline Employment (Self-employed) & $-0.1650^{* * *}$ & $-0.2031^{* * *}$ & -0.0584 . \\
\hline Income $(\mathrm{Q} 1-\mathrm{Q} 2)$ & $0.1893^{* * *}$ & $0.1197^{* * *}$ & $0.2285^{* * *}$ \\
\hline Income (Q2-Q3) & $0.3553^{* * *}$ & $0.3537^{\text {*** }}$ & $0.3268^{* * *}$ \\
\hline Income (Q3-Q4) & $0.3985^{* * *}$ & $0.3795^{* * *}$ & $0.3970^{* * *}$ \\
\hline Income (Q4-Q5) & $0.4101^{* * *}$ & $0.3802^{* * *}$ & $0.4546^{* * *}$ \\
\hline BMI_Status (Normal_weight) & $-0.2730^{* * *}$ & $-0.3482^{* * *}$ & $-0.1616^{* *}$ \\
\hline BMI_Status (Overweight) & $-0.2279^{* * *}$ & $-0.2825^{* * *}$ & $-0.1448^{* *}$ \\
\hline Smoking (Never) & 0.0026 & 0.0307 & -0.0855 \\
\hline Smoking (Occasional) & -0.1088 & -0.0885 & -0.2063 \\
\hline Drinking (Never) & $-0.2720^{* * *}$ & $-0.2144^{* * *}$ & $0.3446^{* * *}$ \\
\hline Drinking (Low_risk) & $-0.1283^{* * *}$ & $-0.1130^{* * *}$ & $0.1448^{* * *}$ \\
\hline Nutrition (Moderate) & 0.0483 & 0.0202 & 0.0836 \\
\hline Nutrition (Sufficient) & $0.1944^{* * *}$ & $0.1669^{* * *}$ & $0.2156^{* * *}$ \\
\hline Health_Status (Good health) & $-1.6318^{* * *}$ & $-1.3185^{* * *}$ & $-1.9090^{* * *}$ \\
\hline Health_Status (Moderate health) & $-1.1286^{* * *}$ & $-1.0346^{* * *}$ & $-1.2304^{* * *}$ \\
\hline Health_Status (Poor health) & $-0.3545^{* * *}$ & $-0.3247^{* * *}$ & $-0.4515^{* * *}$ \\
\hline Test of exogeneity (LR statistics) & $7.89^{* * *}$ & $8.22^{* * *}$ & $5.31^{* *}$ \\
\hline Test of overidentification & 2.26 & 2.85 & 0.62 \\
\hline Number of observations & 16411 & 11969 & 4442 \\
\hline
\end{tabular}

Notes: (1) The reference categories for each independent variables are: 80 years and older (age group for the whole population); 45-64 years (age group for those younger than 65 years old); 80 years and older (age group for those of 65 years and older); female (sex of respondent); primary education level (education); unmarried (legal marital status); unemployed (employment status); less than 1st quintile (income level); obese (BMI status); daily (smoking); high-risk (alcohol consumption risk profile); insufficient (nutrition - fruits and vegetables consumption); very good health (health status). (2) ${ }^{* * *}$ indicate the rejection of null hypothesis for $1 \%$; ${ }^{* *}$ indicate the rejection of null hypothesis for $5 \% ;{ }^{*}$ indicate the rejection of null hypothesis for $10 \%$.

Source: Authors' computation

For the whole population, with the exception of respondents' smoking habits, both socio-economic characteristics and health behaviour were consistently associated with prescription drug use. However, age group and health status prevailed. On the one hand, people in better health were less likely to use prescription drugs compared to those in poorer health. On the other hand, looking at the impact of age, the results show that people were more likely to use 
prescribed medication at older ages. Therefore, the considerable heterogeneity within population subgroups justifies further analysis by age group. It is also noteworthy that higher income levels are related to a higher likelihood of using prescription medicines.

As far as the adult group is concerned, the same conclusions can be drawn. Except for the strong impact of health status, age, and income on the use of prescription drugs, our results also indicate that women are slightly higher users than men, as well as those respondents with tertiary education compared to those with primary education. Finally, the significant impact of some health behavior factors indicates that adopting a healthier lifestyle could lead to less use of prescription drugs.

Similar to the previous cases, that of the whole population and that of the adult group, in the case of the 65+ age group, the most substantial impact on the outcome variable is related to health status and income level. Therefore, lower use of prescription drugs is significantly associated with better health status and lower income respectively. Within this particular group, other significant differences are found between people aged 65-74 and those aged 80 and over, as well as in relation to some behavioural determinants.

The modelling findings on the association between the use of non-prescribed medicines and the socio-economic, health status and health behavioural factors are provided in Table 3 in Column (2) for the whole population, Column (3) for adults group, and Column (4) for the elderly group.

Table 3 The association between non-prescribed medicine use and its determinants, in total population and stratified by age group

\begin{tabular}{|lccc|}
\hline & Total & $\begin{array}{c}\text { < } \\
\text { Variables }\end{array}$ & Years Age \\
& Group & $\begin{array}{c}\text { ６5 Years Age } \\
\text { Group }\end{array}$ \\
\cline { 2 - 4 } & Probit Model & Probit Model & $\begin{array}{c}\text { iecursive Bivariate } \\
\text { Probit Model }\end{array}$ \\
\hline Intercept & -0.3643 & -0.3815 & -0.7442 \\
Age (15-24) & -0.1237 & 0.1485 & - \\
Age (25-44) & -0.1615 & 0.0374 & - \\
Age (45-64) & -0.1409 & - & - \\
Age (65-74) & -0.1499 & - & -0.2280 \\
Age (75-79) & -0.0564 & - & -0.1254 \\
Gender (Male) & -0.4008 & -0.5007 & -0.1629 \\
Education (Secondary) & 0.0393 & 0.0570 & -0.0388 \\
Education (Tertiary) & 0.1525 & 0.0589 & -0.0171 \\
Marital_Status (Divorced) & 0.1364 & 0.1103 & 0.1524 \\
Marital_Status (Married) & 0.1545 & 0.1387 & 0.1282 \\
Marital_Status (Widowed) & 0.0848 & 0.0680 & 0.1277 \\
Employment (Employed) & -0.0321 & -0.0410 & - \\
\hline
\end{tabular}




\begin{tabular}{|lrrr|}
\hline Employment (Self-employed) & 0.1470 & 0.1593 & 0.1357 \\
Income (Q1-Q2) & 0.0650 & 0.0680 & 0.0823 \\
Income (Q2-Q3) & 0.0973 & 0.1001 & 0.0458 \\
Income (Q3-Q4) & 0.2106 & 0.2361 & 0.1408 \\
Income (Q4-Q5) & 0.2672 & 0.3021 & 0.1717 \\
BMI_Status (Normal_weight) & -0.1543 & -0.0685 & -0.1581 \\
BMI_Status (Overweight) & -0.1047 & -0.0279 & -0.1058 \\
Smoking (Never) & -0.0483 & -0.0430 & -0.1826 \\
Smoking (Occasional) & 0.1546 & 0.1963 & -0.3574 \\
Drinking (Never) & -0.3082 & -0.4002 & -0.1054 \\
Drinking (Low_risk) & -0.0883 & -0.1288 & -0.0115 \\
Nutrition (Moderate) & 0.0560 & 0.0838 & 0.0028 \\
Nutrition (Sufficient) & 0.0697 & 0.0968 & 0.0200 \\
Health_Status (Good health) & -0.8439 & -0.7503 & -1.6729 \\
Health_Status (Moderate health) & -0.5842 & -0.5011 & -0.6308 \\
Health_Status (Fair health) & -0.3051 & -0.2190 & -0.3377 \\
Test of exogeneity(LR statistics) & 2.45 & 0.37 & 4.52 \\
Test of overidentification & 2.13 & 1.77 & 1.72 \\
Number of observations & 16411 & 11969 & 4399 \\
\hline
\end{tabular}

Notes: (1) The reference categories for each independent variables are: 80 years and older (age group for the whole population); 45-64 years (age group for those younger than 65 years old); 80 years and older (age group for those of 65 years and older); female (sex of respondent); primary education level (education); unmarried (legal marital status); unemployed (employment status); less than 1st quintile (income level); obese (BMI status); daily (smoking); high-risk (alcohol consumption risk profile); insufficient (nutrition - fruits and vegetables consumption); very good health (health status). (2) ${ }^{* * *}$ indicate the rejection of null hypothesis for $1 \%$; ${ }^{* *}$ indicate the rejection of null hypothesis for $5 \% ;{ }^{*}$ indicate the rejection of null hypothesis for $10 \%$.

Source: Authors' computation

The modelling results on non-prescribed medicine use that pertain to the whole population show that lower use of non-prescribed medicines was associated with young and adult age groups, with male respondents, with lower levels of education, unmarried individuals, lower levels of income, healthier life style (with normal weights, no risky drinking habits, and with a healthy diet), and with a better health status.

Among respondents under 65 years, the use of over-the-counter medicines is generally explained by the same factors. The only exception is education level, body mass index status, dietary habits, which do not have a significant impact on the use of non-prescription medicines. Furthermore, taking into account age group and marital status, the only significant differences in the use of non-prescription medicines are observed between the youngest age group and the group of individuals aged 45-64 years on the one hand, and between married and unmarried respondents on the other. 
Within the older adult group, the results suggest fewer significant associations between the use of non-prescription drugs and various respondents' characteristics. Significant and strong differences are found in relation to age groups, higher income levels, smoking habits, and especially health status. Although gender remains a significant determinant, the difference between male and female respondents is smaller in magnitude for the older population.

Analyzing in the context of the existing literature, we can conclude that our findings are generally in line with other studies conducted on the identification of determinants of drug use. In this respect, a lower consumption of prescribed and non-prescribed medicines is highly associated to better health status of individuals (Vogler et al.,2015). Results on the impact of age on medication use also reveal that older individuals are higher users of medications than their counterparts, but they consume more prescription than non-prescription medications (Vogler et al.,2015). Regardless of age group, our findings are in compliance with other studies revealing that women consume more medicines than men (Daban et al.,2010; Carrasco-Garrido et al.,2014; Vogler et al.,2015). However, among the elderly population, this difference regarding the consumption of prescribed medication does not remain significant, which contrasts with the existing results in the literature, but which may support the hypothesis of this study that stratifying the population by age group allows to better highlight the specificity of medication use in relation to its determinants. Regarding the level of education, our results are not consistent with the literature which claims that it is more likely for those with a lower levels of education to consume prescribed medications (Nielsen et al.,2003; Mayer and Österle,2015), while more educated people are more inclined to consume non-prescription drugs (Carrasco-Garrido et al.,2014; Vogler et al.,2015). In the case of Romania, the results of our study show significant differences between people with tertiary level of education and those with primary level, but the former tend to be higher consumers for both types of drugs. This perspective can be supported to some extent by the impact of income level, which indicates a higher consumption of both prescription and non-prescription medicines as income increases. These results are in agreement with Daban et al. (2010) and Vogler et al. (2015) regarding the consumption of prescription drugs, but in contradiction for the use of non-prescription drugs which is not significantly related to income level according to Vogler et al. (2015). Furthermore, the findings on the impact of employment status also align with the existing literature, suggesting that those who do not work tend to consume more prescription drugs (Mayer and Österle,2015). For non-prescription medication, differences between categories defined by 
employment status are only evident among the self-employed compared to the unemployed. Finally, based on the results obtained on the impact of health behavioural factors, we could conclude that the adoption of a healthier lifestyle could lead to a significant decrease in the use of prescribed medicines, regardless of age group, as well as in the consumption of non-prescription drugs, but especially for the adult population.

\section{Concluding Remarks}

The fundamental aim of this study was to examine the relationship between medicine use and several socio-economic, health behaviour and health related factors in a nationally representative sample of people aged 15 years and over. The contribution of the paper to the existing literature is mainly highlighted by relating the objective of identifying the main determinants of medication use to the context of the Romanian public health system. From this point of view, it is emphasized the need to develop and implement projects, campaigns or public policies targeting in particular vulnerable groups of the population in order to ensure their access to health services, implicitly to the use of prescribed and non-prescribed medicines.

In this context, our empirical findings underline that the determinants of medicine use in the Romanian population depend on the type of drug and especially on the age group. Moreover, the results related to income, education, health behaviour or preventive health measures could play an important role in the development and implementation of such public health policies. However, these recommendations should be addressed separately according to the specificities and determinants most relevant for each type of medicine use and for each age group.

This study is not without limitations. In this regard, noteworthy is the selfreported nature of the data, particularly related to health status and non-prescribed medications, leading to the possibility of response bias due to inaccurate recall or social desirability. In addition, the cross-sectional nature of the data limits the exploitation of reverse causality. In this case, controlling for potential endogeneity of health status would be a difficult task as it involves the use of instrumental variable estimation. Therefore, another limitation of our study is actually related to the choice of these variables, which again depends on the survey data used. 


\section{REFERENCES}

1. Ancelot, Lydie, Liliane Bonnal and Marc-Hubert Depret (2018), "Renoncer aux soins périnataux: quelles conséquences sur l'état de santé du nourrisson?", Revue Economique, Vol. 69, No. 3, pp. 373-405.

2. Ancelot, Lydie, Liliane Bonnal, Greivis Buitrago Gamez, Marc-Hubert Depret and Marion Dupuy (2019), "Vieillissement, état de santé et accident de la vie courante." Revue Française d'Economie, Presses de Sciences-Po, Vol. 34, No. 4, pp. 151-99.

3. Carrasco-Garrido, Pilar, Rodrigo Jiménez-Garcia, Valentín Hernandez-Barrera, A. Gil-deMiguel (2008), "Predictive Factors of Self-medicated Drug Use Among the Spanish Adult Population”, Pharmacoepidemiology and Drug Safety, Vol. 17, pp. 193-119.

4. Daban, Ferran, M. Isabel Pasarín, Maica Rodríguez-Sanz, Anna García-Altés, Joan R. Villalbí, Corinne Zara and Carme Borrell (2010), "Social Determinants of Prescribed and Nonprescribed Medicine Use”, International Journal for Equity in Health, Vol. 9, No. 12.

5. Deschepper, Reginald, Larissa Grigoryan, Cecilia Stålsby Lundborg, Geert Hofstede, Joachim Cohen, Greta Van Der Kelen, Luc Deliens and Flora M. Haaijer-Ruskamp (2008), “Are Cultural Dimensions Relevant for Explaining Cross-national Differences in Antibiotic Use in Europe?", BMC Health Services Research, Vol. 8, No. 123.

6. Eggen, Anne Elise (1994), "Pattern of Drug Use in a General Population - Prevalence and Predicting Factors: The Tromso Study.”, International Journal of Epidemiology, Vol. 23, No. 6, pp. 1262-1272.

7. Eggen, Anne Elise (1997), "Patterns of Medicine Use in a General Population (0 $0 \pm 80$ years). The Influence of Age, Gender, Diseases and Place of Residence on Drug Use in Norway", Pharmacoepidemiology and Drug Safety, Vol. 6, No. 3, pp. 179-187.

8. Elekes, Zsuzsanna and László Kovács (2002), "Old and New Drug Consumption Habits in Hungary, Romania and Moldova", European Addiction Research, Vol. 8, No. 4, pp. 166-169.

9. European Commission (2019), State of Health in the EU-Romania. Country Health Profile,https://www.oecd-ilibrary.org/docserver/f345b1db-

en.pdf?expires $=1638305948 \&$ id=id $\&$ accname $=$ guest $\&$ checksum $=45767 \mathrm{DEF} 08 \mathrm{AB} 8 \mathrm{C} 5 \mathrm{FB} 8351$ 6CF6B97EEB8, [Accessed 17.07.2021]

10. Furu, K., B. Straume and D.S. Thelle (1997), "Legal Drug Use in a General Population: Association with Gender, Morbidity, Health Care Utilization, and Lifestyle Characteristics", Journal of Clinical Epidemiology, Vol. 50, No. 3, pp. 341-349.

11. Jemna, Dănuț-Vasile and Mihaela David (2020), "The Association between Self-reported Health Status and Physical Activity: Evidence from Romania", Journal of Public Administration, Finance and Law, No. 17, pp. 214-232.

12. Johnson, Richard and Clyde R. Pope (1983), "Health Status and Social Factors in Nonprescribed Drug Use.", Medical Care, Vol. 21, No. 2, pp. 225-233.

13. Geva, Liat Lerner, Tzvia Blumstein, Valentina Boyko, Adel Farhi and Yael Benyamini (2016), "Cultural Disparities in the Use of Prescription and Nonprescription Medications among Midlife Women in Israel", International Journal of Health Services, Vol. 47, No. 3.

14. Maddala, Gangadharrao Soundalyarao (1983), Limited-Dependent and Qualitative Variables in Econometrics, New-York: Cambridge University Press.

15. Manole, Mugur, , Duma Odette, Anca Gheorma, Alina Manole, Ioana Pavaleanu, Natalia Velenciuc, Liliana Chelaru and Letiția-Doina Duceac (2017), "Self-medication - A Public Health Problem in Romania Nowadays. The First Quests", The Medical-Surgical Journal, Vol.121, No. 3, pp. 608-615. 
16. Mayer, Susanne and August Österle (2015), "Socioeconomic determinants of prescribed and non-prescribed medicine consumption in Austria", European Journal of Public Health, Vol. 25, No. 4, pp. 597-603.

17. Molarius, Anu, Kenneth Berglund, Charli Eriksson, Mats Lambe, Eva Nordström, Hans G. Eriksson and Inna Feldman (2007), "Socioeconomic Conditions, Lifestyle Factors, and Selfrated Health among Men and Women in Sweden", European Journal of Public Health, Vol. 17, No. 2, pp. 125-133.

18. Nielsen, Merete W. and Ebba Holme Hansen (2003), „Prescription and Non-prescription Medicine Use in Denmark: Association with Socio-economic Position", European Journal of Clinical Pharmacology, Vol. 59, pp. 677-684.

19. Rocca, Patricia, Anders Beckman, Eva Ekvall Hansson and Henrik Ohlsson (2015), "Is the Association between Physical Activity and Healthcare Utilization Affected by Self-rated Health and Socio-economic Factors?", BMC Public Health, Vol. 15, 737.

20. Tarciuc, Petruta, Ana Maria Alexandra Stanescu, Camelia Cristina Diaconu, Luminita Paduraru, Alina Duduciuc and Smaranda Diaconescu (2020), "Patterns and Factors Associated with SelfMedication among the Pediatric Population in Romania.", Medicina (Kaunas), Vol. 56, No. 6.

21. Vie, Tina Lokke, Karl Ove Hufthammer, Turid Lingaas Holmen, Eivind Meland, Hans Johan Breidablik (2018), "Is Self-rated Health in Adolescence a Predictor of Prescribed Medication in Adulthood? Findings from the Nord Trøndelag Health Study and the Norwegian Prescription Database", SSM - Population Health, Vol. 4, pp. 144-152.

22. Vogler, Sabine, August Österle and Susanne Mayer (2015), "Inequalities in Medicine use in Central Eastern Europe: An Empirical Investigation of Socioeconomic Determinants in Eight Countries.", International Journal for Equity in Health, Vol. 14, No. 124. 


\section{APPENDIX}

Table A1 Distribution of individuals according to their characteristics and the use of prescribed medicines, in total population and stratified by age group

\begin{tabular}{|c|c|c|c|c|c|c|}
\hline \multirow[t]{2}{*}{ Variables } & \multicolumn{2}{|c|}{ Total } & \multicolumn{2}{|c|}{$\begin{array}{c}<65 \text { Years Age } \\
\text { Group }\end{array}$} & \multicolumn{2}{|c|}{$\begin{array}{c}\geq 65 \text { Years Age } \\
\text { Group }\end{array}$} \\
\hline & No $(\%)$ & Yes $(\%)$ & No $(\%)$ & Yes $(\%)$ & No $(\%)$ & Yes $(\%)$ \\
\hline Age (15-24) & 13.68 & 0.87 & 16.07 & 2.17 & - & 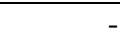 \\
\hline Age (25-44) & 36.40 & 4.60 & 42.76 & 11.46 & - & - \\
\hline Age (45-64) & 35.04 & 34.68 & 41.16 & 86.37 & - & - \\
\hline Age (65-74) & 9.16 & 28.92 & - & - & 61.55 & 48.32 \\
\hline Age (75-80) & 4.92 & 25.75 & - & - & 33.07 & 43.02 \\
\hline Age $(80+)$ & 0.80 & 5.18 & - & - & 5.37 & 8.66 \\
\hline Sex (Female) & 49.76 & 60.14 & 49.21 & 60.79 & 52.96 & 59.70 \\
\hline Sex (Male) & 50.24 & 39.86 & 50.79 & 39.21 & 47.04 & 40.30 \\
\hline Education (Primary) & 7.44 & 23.22 & 3.10 & 5.62 & 32.24 & 35.04 \\
\hline Education (Secondary) & 79.87 & 69.18 & 82.85 & 84.20 & 62.83 & 59.10 \\
\hline Education (Tertiary) & 12.69 & 7.59 & 14.05 & 10.18 & 4.93 & 5.86 \\
\hline Marital_Status (Unmarried) & 8.53 & 30.42 & 3.41 & 11.07 & 37.78 & 43.40 \\
\hline Marital_Status (Divorced) & 26.63 & 4.53 & 30.86 & 8.73 & 2.49 & 1.72 \\
\hline Marital_Status (Married) & 58.99 & 60.79 & 59.48 & 73.03 & 56.18 & 52.57 \\
\hline Marital_Status (Widower) & 5.85 & 4.27 & 6.25 & 7.17 & 3.55 & 2.31 \\
\hline Employment (Unemployed) & 41.77 & 80.91 & 33.20 & 60.79 & 90.75 & 94.40 \\
\hline Employment (Employed) & 42.48 & 12.17 & 49.79 & 29.42 & 0.72 & 0.60 \\
\hline Employment (Self-Employed) & 15.75 & 6.92 & 17.01 & 9.79 & 8.53 & 5.00 \\
\hline Income $(<1$ st quintile $)$ & 19.72 & 17.89 & 18.34 & 13.96 & 27.59 & 20.52 \\
\hline Income (1st - 2nd quintile) & 18.98 & 23.25 & 17.29 & 17.96 & 28.64 & 26.79 \\
\hline Income (2nd - 3rd quintile) & 19.69 & 21.97 & 19.60 & 21.69 & 20.22 & 22.16 \\
\hline Income (3rd -4 th quintile) & 19.74 & 19.85 & 20.86 & 23.47 & 13.35 & 17.43 \\
\hline Income (4th -5 th quintile) & 21.87 & 17.04 & 23.91 & 22.91 & 10.19 & 13.10 \\
\hline BMI_Status (Normal_weight) & 47.05 & 34.14 & 90.01 & 9.99 & 38.62 & 61.38 \\
\hline BMI_Status (Overweight) & 46.02 & 49.31 & 83.78 & 16.22 & 43.08 & 56.92 \\
\hline BMI_Status (Obese) & 53.13 & 46.87 & 65.01 & 34.99 & 33.45 & 66.55 \\
\hline Smoking (Never) & 68.93 & 31.07 & 83.19 & 16.81 & 39.34 & 60.66 \\
\hline Smoking (Occasional) & 88.25 & 11.75 & 91.71 & 8.29 & 55.95 & 44.05 \\
\hline Smoking (Daily) & 85.63 & 14.37 & 89.32 & 10.68 & 50.86 & 49.14 \\
\hline Drinking (Never) & 64.26 & 35.74 & 81.25 & 18.75 & 32.75 & 67.25 \\
\hline Drinking (Low_risk) & 78.28 & 21.72 & 86.71 & 13.29 & 46.90 & 53.10 \\
\hline Drinking (High_risk) & 82.10 & 17.90 & 89.19 & 10.81 & 55.61 & 44.39 \\
\hline Nutrition (Insufficient) & 72.44 & 27.56 & 85.62 & 14.38 & 46.79 & 53.21 \\
\hline Nutrition (Moderate) & 72.92 & 27.08 & 86.51 & 13.49 & 41.36 & 58.64 \\
\hline Nutrition (Sufficient) & 73.93 & 26.07 & 84.17 & 15.83 & 37.20 & 62.80 \\
\hline Health_status (Bad) & 1.60 & 27.29 & 0.69 & 19.97 & 6.81 & 32.02 \\
\hline Health_status (Moderate) & 13.42 & 54.76 & 7.28 & 50.39 & 48.59 & 57.69 \\
\hline Health_status (Good) & 48.19 & 17.22 & 49.39 & 28.03 & 41.33 & 9.96 \\
\hline Health_status (Very good) & 36.79 & 0.74 & 42.65 & 1.61 & 3.27 & 0.15 \\
\hline
\end{tabular}

Source: Authors' computation 
Table A2 Distribution of individuals according to their characteristics and the use of non-prescribed medicines, in total population and stratified by age group

\begin{tabular}{|c|c|c|c|c|c|c|}
\hline \multirow[t]{2}{*}{ Variables } & \multicolumn{2}{|c|}{ Total } & \multicolumn{2}{|c|}{$\begin{array}{c}<65 \text { Years Age } \\
\text { Group }\end{array}$} & \multicolumn{2}{|c|}{$\begin{array}{c}\geq 65 \text { Years Age } \\
\text { Group }\end{array}$} \\
\hline & No (\%) & Yes (\%) & No $(\%)$ & Yes $(\%)$ & No $(\%)$ & Yes $(\%)$ \\
\hline Age (15-24) & 11.0 & 6.0 & 14.82 & 9.19 & - & \\
\hline Age (25-44) & 29.0 & 21.6 & 38.98 & 32.97 & - & \\
\hline Age (45-64) & 34.4 & 38.0 & 46.20 & 57.84 & - & \\
\hline Age (65-74) & 13.9 & 17.4 & - & - & 54.42 & 50.60 \\
\hline Age (75-84) & 9.8 & 14.3 & - & - & 38.36 & 41.60 \\
\hline Age $(85+)$ & 1.8 & 2.7 & - & - & 7.22 & 7.79 \\
\hline Sex (Female) & 50.4 & 63.8 & 48.52 & 65.25 & 55.96 & 61.03 \\
\hline Sex (Male) & 49.6 & 36.2 & 51.48 & 34.75 & 44.04 & 38.97 \\
\hline Education (Primary) & 11.3 & 14.0 & 3.44 & 3.68 & 34.00 & 33.59 \\
\hline Education (Secondary) & 77.6 & 73.8 & 83.41 & 80.93 & 60.72 & 60.15 \\
\hline Education (Tertiary) & 11.1 & 12.3 & 13.15 & 15.39 & 5.29 & 6.26 \\
\hline Marital_Status (Unmarried) & 13.7 & 18.1 & 4.37 & 5.57 & 40.91 & 42.04 \\
\hline Marital_Status (Divorced) & 22.2 & 12.7 & 29.09 & 18.55 & 2.18 & 1.43 \\
\hline Marital_Status (Married) & 58.7 & 63.7 & 60.22 & 69.10 & 54.17 & 53.46 \\
\hline Marital_Status (Widower) & 5.4 & 5.5 & 6.32 & 6.78 & 2.74 & 3.07 \\
\hline Employment (Unemployed) & 51.4 & 57.3 & 37.00 & 39.06 & 93.12 & 92.21 \\
\hline Employment (Employed) & 35.3 & 29.3 & 47.21 & 44.11 & 0.59 & 0.88 \\
\hline Employment (Self-Employed) & 13.4 & 13.4 & 15.79 & 16.83 & 6.30 & 6.92 \\
\hline Income $\left(<1^{\text {st }}\right.$ quintile $)$ & 19.6 & 17.3 & 18.14 & 14.99 & 23.81 & 21.62 \\
\hline Income $\left(1^{\text {st }}-2^{\text {nd }}\right.$ quintile $)$ & 20.1 & 20.4 & 17.53 & 16.60 & 27.50 & 27.66 \\
\hline Income $\left(2^{\text {nd }}-3^{\text {rd }}\right.$ quintile $)$ & 20.7 & 18.1 & 20.38 & 17.12 & 21.71 & 20.09 \\
\hline Income $\left(3^{\text {rd }}-4^{\text {th }}\right.$ quintile $)$ & 19.5 & 21.2 & 20.94 & 23.09 & 15.36 & 17.45 \\
\hline Income $\left(4^{\text {th }}-5^{\text {th }}\right.$ quintile $)$ & 20.1 & 23.0 & 23.02 & 28.20 & 11.61 & 13.17 \\
\hline BMI_Status (Normal_weight) & 85.54 & 14.46 & 86.85 & 13.15 & 80.82 & 19.18 \\
\hline BMI_Status (Overweight) & 83.35 & 16.65 & 85.04 & 14.96 & 79.36 & 20.64 \\
\hline BMI_Status (Obese) & 80.46 & 19.54 & 81.95 & 18.05 & 77.98 & 22.02 \\
\hline Smoking (Never) & 83.58 & 16.42 & 85.52 & 14.48 & 79.56 & 20.44 \\
\hline Smoking (Occasional) & 82.49 & 17.51 & 82.14 & 17.86 & 85.71 & 14.29 \\
\hline Smoking (Daily) & 86.23 & 13.77 & 87.06 & 12.94 & 78.35 & 21.65 \\
\hline Drinking (Never) & 84.91 & 15.09 & 87.94 & 12.06 & 79.30 & 20.70 \\
\hline Drinking (Low_risk) & 82.95 & 17.05 & 83.85 & 16.15 & 79.61 & 20.39 \\
\hline Drinking (High_risk) & 84.15 & 15.85 & 85.11 & 14.89 & 80.57 & 19.43 \\
\hline Nutrition (Insufficient) & 85.75 & 14.25 & 88.33 & 11.67 & 80.45 & 19.55 \\
\hline Nutrition (Moderate) & 84.12 & 15.88 & 85.78 & 14.22 & 79.84 & 20.16 \\
\hline Nutrition (Sufficient) & 83.52 & 16.48 & 84.92 & 15.08 & 79.32 & 20.68 \\
\hline Health_status (Bad) & 7.4 & 14.7 & 3.15 & 5.91 & 19.56 & 31.50 \\
\hline Health_status (Moderate) & 23.1 & 32.4 & 12.37 & 21.42 & 54.17 & 53.46 \\
\hline Health_status (Good) & 40.3 & 37.3 & 45.75 & 49.05 & 24.54 & 14.93 \\
\hline Health_status (Very good) & 29.3 & 15.5 & 38.73 & 23.61 & 1.73 & 0.11 \\
\hline
\end{tabular}

Source: Authors' computation 